\title{
LIVELIHOOD DIVERSIFICATION AND CLIMATE CHANGE ADAPTATIONIN INDO-GANGETIC PLAINS: IMPLICATION OF RAINFALL REGIMES
}

\author{
Gopal D Bhatta ${ }^{1}$; Pramod K Aggarwal ${ }^{2}$ and Amit Shrivastava ${ }^{3}$
}

\begin{abstract}
We investigate whether spatial variations in climatic resource such as rainfall have prompted livelihood diversification, local adaptation and household food availability in Indo-Gangetic Plains using data from a household survey of 2660 farm-families carried out in India, Bangladesh and Nepal. We found that on-farm livelihood sources are higher in high rainfall regime $(1300-1800 \mathrm{~mm})$ compared to medium ( $<1300 \mathrm{~mm}$ ) and very high rainfall regime(>1800 mm). The off-farm sources are higher in medium rainfall regime. Although a large number of changes are attributed to harvest better yield, yet farmers made numbers of changes in response to climatic variability as well. Although agricultural livelihood and local adaptation are restrained by several climatic and nonclimatic factors; the amount of annual rainfall significantly affects livelihood diversification, and the impact of climatic stressors becomes more pronounced when there is interaction with other nonclimatic factors. The results imply that livelihood and adaptation strategies should be tailor made along the climatic and non-climatic resources.
\end{abstract}

Key words: Adaptation, Climate change, Indo-Gangetic Plain, Livelihood diversification, Rainfall regime

\section{INTRODUCTION}

The Indo-Gangetic Plains (IGP), a "bread basket" for much of South Asia, is considered to be highly vulnerable to climate change due to its huge population, a largely agrarian economy, a relatively limited and depleting resource base, and projected large changes in climatic risks (New et al., 2012; Saini, 2008; Aggarwal et al., 2004). While the region is self-reliant on cereal production, it has pervasive poverty and malnourishment (Gill et al, 2003; FAO, 2002). The changing climate is exacerbating existing vulnerabilities of the subsistence farming that predominates in many parts of IGP (Nelson et al., 2009; IPCC, 2007; Slingo et al., 2005).

Climate-related issues and farmers' livelihood strategies are different in different parts of IGP. For instance, many farmers in Nepal and north east India suffer from droughts and intermittent floods whereas coastal Bangladesh is a 'hotspot' of climate change (Nicholls et al., 2007).As an attempt to overcome some of the climatic and non-climatic challenges, farm households diversify their livelihood sources (Brown et al., 2006; UNDP, 2009). Several researchers (e.g. Bhatta and Aggarwal, 2015; Teweldemedhin and Kapimbi, 2012; Hailu and

\footnotetext{
${ }^{1}$ First author conducted this study when he was affiliated with CGAIR Program on Climate Change, Agriculture and Food Security (CCAFS), South Asia. Current affiliation: The City of Calgary, Alberta, Canada; corresponding author's email: bhattagopal@gmail.com.

${ }^{2}$ Regional Team Leader, CCAFS South Asia, International Water Management Institute, New Delhi, India.

${ }^{3} \mathrm{GIS}$ and Remote Sensing Specialist, CIMMYT, New Delhi, India.
} 
Hasan, 2012; Barrett et al., 2006; Marschke and Berkes, 2006; Barrett and Reardon, 2001) offer the reason that farm households follow agricultural diversification as a prominent coping strategy under uncertainty caused by climatic and non-climatic factors.

Coping with climatic variability is crucial to adapting to the changing environmental conditions, including climate change and variability (Cooper et al., 2008). Diversification on the farm and off-farm determine the strength of coping strategies farm households follow (Hailu and Hasan, 2012; Gebru and Beyene, 2012; Thornton et al., 2007); the larger the diversification portfolio on the farm and off-farm, the more successful are the farmers in coping adversities which in turn contributes to adaptation. Similarly, the strategies that have been shown to increase agricultural productivity and adaptation to climatic variability include integrated plant management practices and integrated farming systems (Hesterman and Thorburn, 1994), expansion of areas under cultivation to compensate for reduced yields during droughts, and switching to more drought resistant crops (Mongi et al., 2010), resource-conserving technologies (Harington and Hobbs, 2009; Ladha et al., 2009; Gupta and Seth, 2007), and enhancing water use efficiency. In addition, other farming practices that are important in response to the climatic risks are better management of the pasture lands, adoption of drought tolerant pasture species, better livestock management practices, cultivation of drought and flood tolerant varieties of the crops, disease and pest resistant cultivars, shorter cycle varieties, introduction of crop cover, planting trees, among others. Development of location-specific varieties, climate specific agronomic practices, and adoption of short season varieties to escape the late season droughts are some of the other adaptation strategies amidst climate change scenario (Bhatta and Aggarwal, 2015; Chhetri and Easterling, 2012).

The relationship between average annual rainfall, and farmers' livelihood,and local adaptation could be a matter of interest for many scholars to devise policies aiming at improving livelihoods and enhancing adaptive capacity of the farmers at the spatial level. It is because some environmental issues and threats posed by climate change to livelihoods are likely to be spatially variable and solution to such problems may often require supranational considerations (GECAFS, 2008) based on spatial specificities. Since IGP possesses varied agro-ecological and biophysical conditions such as a distinct rainfall pattern from east to west of the region, farmers' strategies to manage available resources also differ. Since a large proportion of farm land in IGP is rainfed, annual rainfall is important not only in determining production but also how farmers in different rainfall regimes cope with climatic variability overtime. It is, therefore, important to understand whether key climatic (rainfall) and non-climatic resources (farm types) impact livelihoods and adaptation amid changing environmental conditions. We attempt to narrow down this gap through an investigation of a household survey carried out with 2660 farm-families in threebroader sub-regions in IGP (Bihar of India, coastal Bangladesh and Terai of Nepal). We hope that this study would provide policy makers and sectoral actors with process knowledge that could improve coping and adaptation strategies for climate change. 


\section{METHODS AND DATA}

\section{THE SITES AND SAMPLING PROCESS}

A household survey was implemented in 2010-2011 in the three broad agro-ecological regionsin the Indo-Gangetic Plain (IGP) with average annual rainfall ranging from $930 \mathrm{~mm}$ to $3350 \mathrm{~mm}$ (CRU, 2013). The sites surveyed lie in the eastern region, which is characterized by relatively lower productivity, poorly developed infrastructure, food insecurity, smallholder subsistence farming and is prone to flooding and droughts (Aggarwal et al., 2004). The study sub-regions represent climate 'hotspots' (flood and salinity affected areas of coastal Bangladesh to drought prone areas of Nepal's Terai and Bihar, India), rainfall regimes (very high rainfall areas of coastal Bangladesh to high rainfall areas of Terai and moderate rainfall areas of Bihar), and the local livelihood systems (aquaculture based livelihoods in coastal Bangladesh to cereals and vegetables based livelihoods in Terai and Bihar).

The sampling process was done at three different stages (Bhatta and Aggarwal, 2015): I) broader sub-region was selected from India, Nepal and Bangladesh primarily based on similar climatic issues, II) smaller areas (mostly districts) were selected from each subregion based on predominant rainfall pattern (7 districts each from Bihar and coastal Bangladesh and 5 from Terai), and III) finally layering a sampling frame in each site (10 km $\mathrm{x} 10 \mathrm{~km}$ ) was done purposively in each selected district based on the area with some potential of piloting climate smart agriculture interventions. From each sampling frame, all villages were enumerated and 7 villages were selected randomly. Following simple random sampling, 20 households within each village were chosen. Therefore, the total sample size was 980 each in Bihar and coastal Bangladesh and 700 households in Terai.

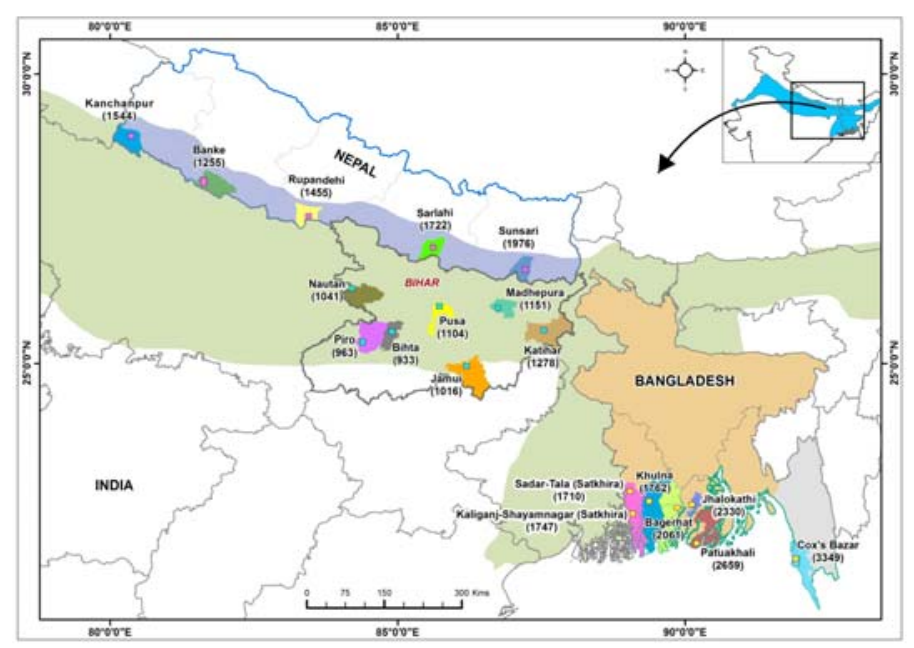

Figure 1. Sites surveyed in Indo-Gangetic Plain (Values in the parenthesis indicate average annual rainfall, $\mathrm{mm}$ ) 


\section{SURVEY INSTRUMENTS AND DATA COLLECTION}

A highly structured questionnaire was designed, pre-tested and the same questionnaire (available at:www.ccafs.cgiar.org/resources/baseline-surveys) was implemented across at all sites. The questionnaire included most of the qualitative information to map the behaviours of the farm households in several spectrums of the farm activities. The questionnaire has different components: socio-demographic information, sources of livelihoods, changes in farming practices including livestock and fisheries over the last 10 years, reasons of changing farming practices, household food availability, land and water resources, input and credit availability and use, climate and weather information, membership to community groups and household assets, among others. Before implementing surveys in each site, site survey team leaders and enumerators were provided with intensive training to ensure high level of precision on sampling and data collection.

\section{DATA ANALYSIS}

The historical rainfall data (1961 to 2010) for this study was extracted from the Climate Research Unit (CRU) gridded database. CRU time-series datasets are month-by-month variations in climate over the last several decades. The dataset comes on high-resolution $(0.5 \times 0.5$ degrees) grids (CRU, 2013). Since the basic interest was to see any variations on livelihoods, adaptation and food available months along the prevalent rainfall gradient; functional relationship was tested. Before running functional relation, normality test was deployed and the variables satisfyingnormal distribution were subjected to functional analysis. In the first step, country-wise regression lines were fitted followed by line of the best fit across all sites using appropriate functional relation. Further to see more variation as per irrigated and non-irrigated farms along the prevalent rainfall gradient, data were disaggregated and appropriate functional relation was tested. For the ease of explanation, different sites were categorized into medium rainfall zone $(<1300 \mathrm{~mm}$ annual rainfall), high rainfall zone $(1300-1800 \mathrm{~mm})$ and very high rainfall zone $(>1800 \mathrm{~mm})$. With this grouping, all of the sites in Bihar of India fall in medium rainfall regime, most of the sites in Terai fall in high rainfall regime and all sites in coastal Bangladesh in veryhigh rainfall zone.A rough proxy for adaptability was derived by adding up the number of changes that households have made in the last 10 years with respect to their farming practices. The idea here is that households that have already been making changes, and introducing new practices, are likely to be more adaptive to climatic risks, than those that have not been able to make adjustments or introduced any new innovations. The number of food available months is used in this analysis which is considered as the best bet proxy of food security at the household level. 


\section{RESULTS}

\section{LIVELIHOOD DIVERSIFICATION}

Farmers derive their livelihoods through a variety of on-farm,non-farm and off-farm sources, and these sources are different across the sites. Majority of the farm-families in the studied sub-regions predominantly pursue agriculture-based livelihood strategies through intensification and diversification. In Bihar and Terai of Nepal, a majority of the farmers derive their livelihoods through food crops whereas livestock including fisheries is an important on-farm livelihood source in coastal Bangladesh. It should also be understood that integration is a historic phenomenon in smallholder farming systems in IGP.

Despite continuing economic centrality of agriculture in the surveyed sites, farm-families are often enforced to pursue off-farm livelihood strategies to cope with diverse challenges and risks and accumulate cash for present and future security. Off-farm sources of livelihoods in IGP are manifold: wage earning from other's farm, employment in several sectors, remittances, credit/loan and business, among others. These off-farm sources of income help farmers to complement agricultural activities. In Bihar, a large proportion of the farm-families are engaged in wage earning either in others' farm and/or in other nonfarm sectors, followed by employment in different sectors. Farmers in the coastal Bangladesh also mostly engaged in wage earning followed by pursuing credit/loans from formal and informal sectors. In Nepal's Terai, a large proportion of farmers are deriving income through employment followed by the wage earning activities. In Bihar and Nepal's Terai, remittance accounts the third important source of off-farm livelihoods while business provides a third off-farm source to the farmers in the coastal Bangladesh.

The sources of on-farm livelihood and rainfall gradient across the sites in each country and across all sites in the region show a polynomial relationship (Figure2a). In Bihar, higher is the average annual rainfall; higher are the sources of livelihoods up to a certain extent. Similar trend turns true in coastal Bangladesh and Terai but the slope of the curve is steeper in Terai. On average, the numbers of livelihood options are higher in Nepal's Terai compared to Bihar and coastal Bangladesh. Although rainfall regime is higher in coastal Bangladesh, several other factors such as salinity, recurrent floods, sea level rise and cyclones limiton-farmlivelihood diversification. 

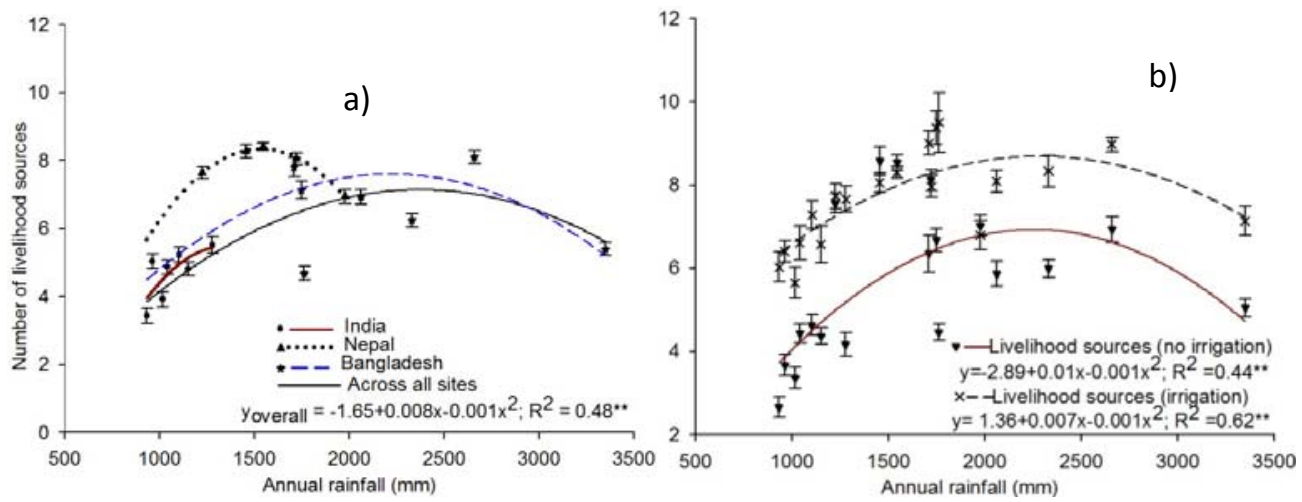

Figure 2. Relationship between annual rainfall, and number of livelihood sources (a) and number of livelihood sources within irrigated and non-irrigated farms (b) in IGP (Error bars indicate the 95\% confidence interval of the mean)

The regression line $\left(R^{2}=48 \%, p<0.01\right)$ across all sites follows sub-region specific regressions, that is, with increasing rainfall regime, number of sources of livelihood also increases up to a certain point. Although there could be several climatic and non-climatic factors affecting on-farm livelihoods, the current results portray that higher rainfall zone (1300-1800 mm) shows higher on-farm diversification. As expected, data disaggregation by irrigated and non-irrigated farms show similar trend and the higher level of diversification is associated to irrigated farms $\left(R^{2}=62 \%, p<0.01\right)$ than rainfed farms $\left(R^{2}=44 \%\right.$, $\mathrm{p}<0.01$ )(Figure2b). The results pinpoint that having irrigation facility serves as a precursor for livelihood diversification on the farm irrespective of the rainfall regime and its effect is more pronounced in higher rainfall zone. It is interesting to note that both regression lines move almost parallel along the rainfall gradient. This portrays, to some extent, that irrigation has homogeneous effect on livelihoods along rainfall regimes.

Rainfall regimes and number of off-farm livelihood sources show a significant polynomial relation (Figure3). Despite the lower rainfall regime, numbers of cash sources are more and they decrease at higher rainfall regime. Farmers in the Bihar, for instance, have more cash sources compared to Terai and coastal Bangladesh. With an increasing rainfall regime, number of sources of cash increases up to a certain extent in Bihar, Terai and coastal Bangladesh but the degree of increment with rainfall regimes is higher in Bihar compared to other sub-regions. Lower number of on-farm livelihood sources and higher number of off-farm sources in medium rainfall regime $(<1300 \mathrm{~mm})$ somehow signifies that farmers are slowly moving out of agriculture. While country-specific regression lines are concave to the origin, overall regression line is convex stating that farmers in relatively lesser rainfall area possess more sources of cash and it declines with increasing rainfall regimes. 


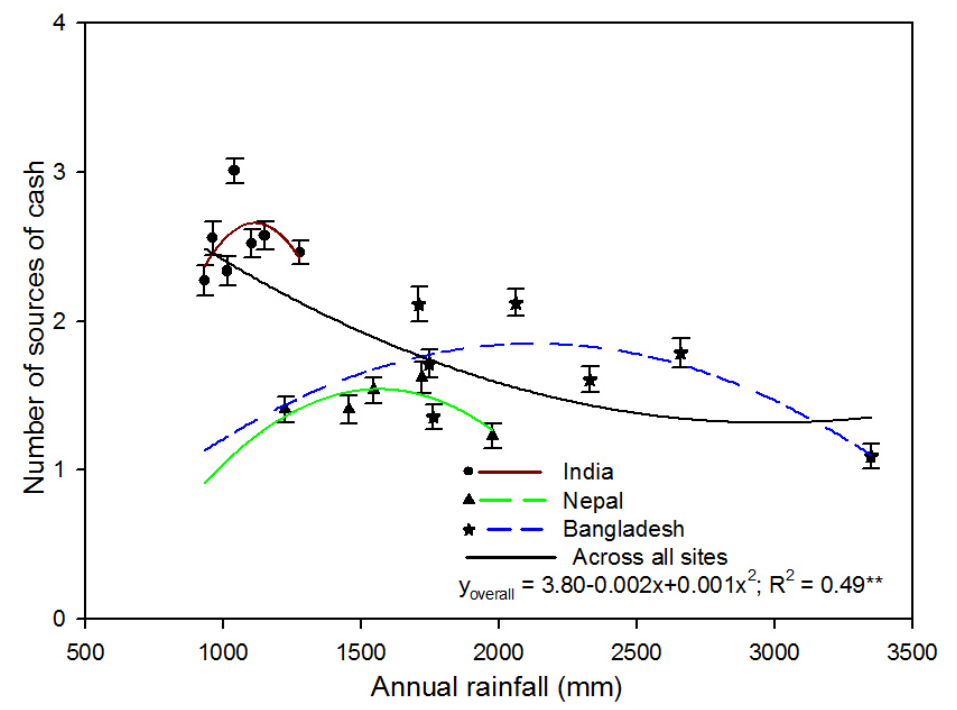

Figure 3. Relationship between annual rainfall and sources of cash (Error bars indicate the 95\% confidence interval of the mean)

\section{FARMING PRACTICES CHANGED AND ADAPTATION TO CLIMATIC RISKS}

The number of changes in farm practices provides a proxy measure of adaptability. We asked farmers different changes they made on variety, breed, crop and livestock management, soil and water management, production practices and feeding, among others. Among the portfolio of changes in farming practices; frequent changes in varieties shows consistence result across sites and a large proportion of the households made several changes in the varieties. Changes in planting time and methods (such as late planting, early planting, early land preparation, mechanized planting) show variations in the sub-region. Changes in plant management (irrigation use and methods, agro-chemical use, and disease and pest management) showed consistent results both in Bihar and Nepal's Terai compared to coastal Bangladesh. A large chunk of the farmers made changes in livestock in coastal Bangladesh.

In Bihar, farming practices changed increases with increasing rainfall regime up to a certain extent. Unlike Bihar, Nepal and coastal Bangladesh show higher number of farming practices changed at a lower rainfall regime. There is no clear trend in terms of changing farming practices along the rainfall gradient across the sites (Figure4a). Number of farming practices changed over the last 10 years as per irrigated and non-irrigated farms along the prevalent rainfall gradient show polynomial relationship with average annual rainfall. With huge variation in irrigated farms, higher numbers of farming practices changed are noted at a medium rainfall regime $(<1300 \mathrm{~mm})$ both in irrigated and rainfed farms (Figure4b). With irrigation, farmers make higher number of changes. This is also substantiated by on-farm 
livelihoods as they are higher in the irrigated farms. However, both lines are statistically not significant $(p>0.05)$.
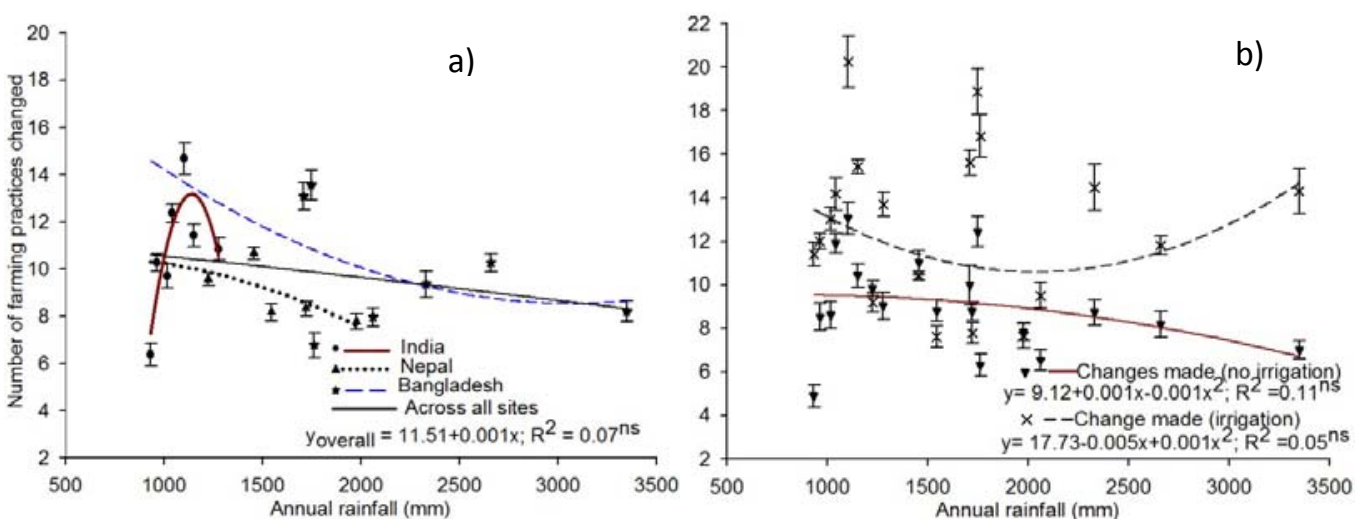

Figure 4. Number of farming practices changed (a) and as per irrigated and non-irrigated farm (b) along the rainfall gradient in IGP (Error bars indicate the $95 \%$ confidence interval of the mean)

Farmers make changes to farm practices in response to different stressors. Subsistence farmers' main interest is to secure on-farm production as an important livelihood strategy. We found that market-related factors are more frequently cited as reasons to changes in farm practices than climate-related factors (Figure5). Harvesting better yield, often by changing crops and/or varieties, remains the top reason for making changes in the farming practices across all regions and rainfall regimes. Issues related to land (e.g., declining fertility), labor (e.g., labor shortages), water (e.g., groundwater decline) and biotic factors (e.g., pest and disease outbreak in the particular crop and/or variety) are often frequently mentioned as reasons for making changes in the crops and/or varieties. Across rainfall gradient, very high rainfall regime $(>1800 \mathrm{~mm})$ shows lesser per cent of farmers making changes to adjust to the resource constraints, markets and climatic stressors but the per cent of farmers making changes to adjust to disasters (floods, cyclones, storm) are increasing. Ahmed et al. (2012) also noted that climatic hazards appear more frequently than other factors in coastal areas of Bangladesh, which requires an adjustment to such adverse events. 

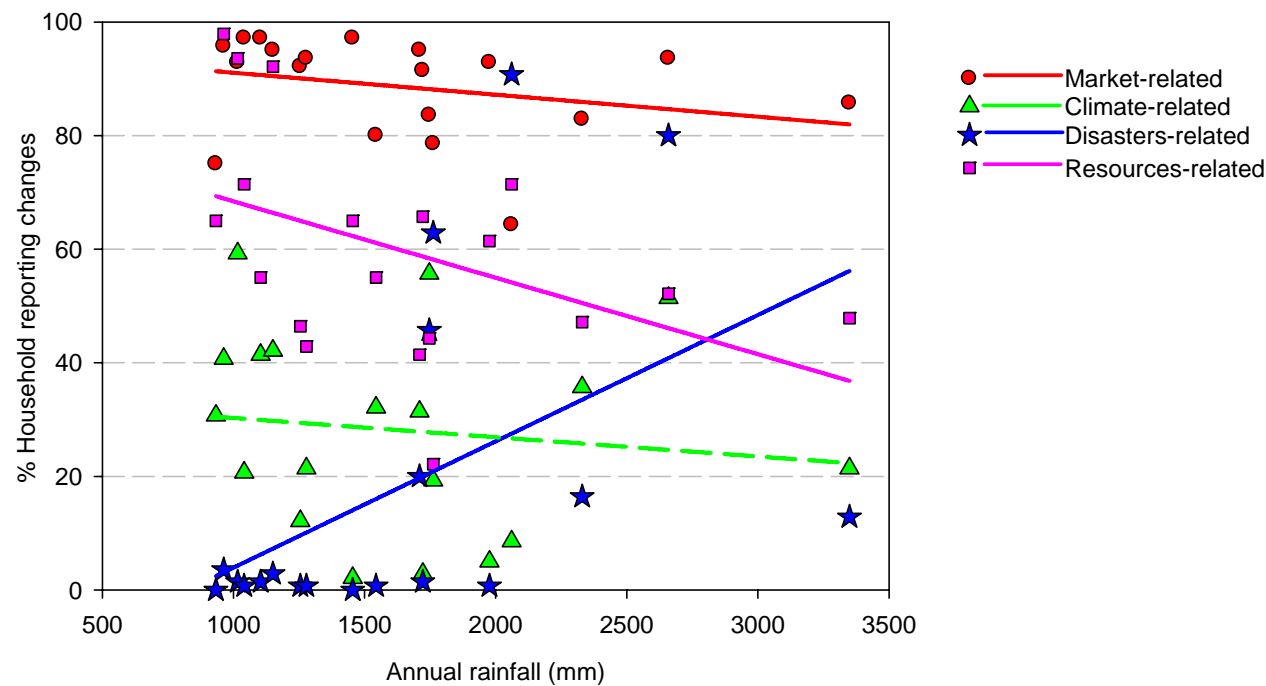

Figure 5. Different drivers of changes to farm practices over the last 10 year across rainfall regimes

In terms of climatic stressors, rainfall variability is the most frequently cited reason for making changes in farming practices in all sub-regions and across all rainfall regimes. Farmers also made frequent changes to adapt to droughts and floods that prevailed in many parts of IGP over the last 10 years. Late or early start of rain is another issue that some farmers in the surveyed areas experience. The growing number of cold spells during the winter season is now becoming another issue requiring adaptation to it in many sites.

\section{HOUSEHOLD FOOD AVAILABILITY}

We studied the number of food available monthsin a normal year. As we just studied number of food available months during a year, it only provides the food availability status in the household and through own farm production. With a large site variations, a majority of the farmers in the coastal Bangladesh support only a fraction of the year through own production. In contrast to this, a majority of the farmers in Bihar and Terai can produce food for their family almost throughout the year (almost $75 \%$ and $80 \%$ of the farm households in Nepal and Bihar are self-sufficient). Lower productivity of the crops, dominance of smallholder farmers and fewer number of livelihood sources are all contributing towards fewer months of food availability in the coastal Bangladesh.

With increasing rainfall regime, number of food available months increases in Bihar and Nepal's Terai (Figure6a). Coastal Bangladesh fails to show a clear pattern. The high rainfall regime in Bihar and Nepal shows higher months of food availability like on-farm livelihood sources. This supports the idea that more livelihood sources on the farm enhance 
household food availability. The overall regression line shows the higher number of food available months in a year at medium rainfall regime, which is basically due to the more food available months in Bihar. Since much of the household food availability in IGP revolves around the availability of rice and wheat, the lower production of these crops means less number of food available months. In the coastal Bangladesh, for instance, seasonal flooding due to heavy monsoon rain along with salinity intrusion causes frequent crop failure. Even in the dry season, there is the lack of fresh water for crop production (Karim and Mimura, 2008; Mirza et al., 2003). These all factors threaten on-farm production and household food availability. Farmers who have irrigation facility have more number of food available months than those who perform farming without irrigation facility. In both cases, relationship with rainfall is polynomial, that is, as rainfall regimes increase, the number of food available months decrease (Figure6b). Farmers with no irrigation facility show higher variations along the spatial gradient of rainfall.

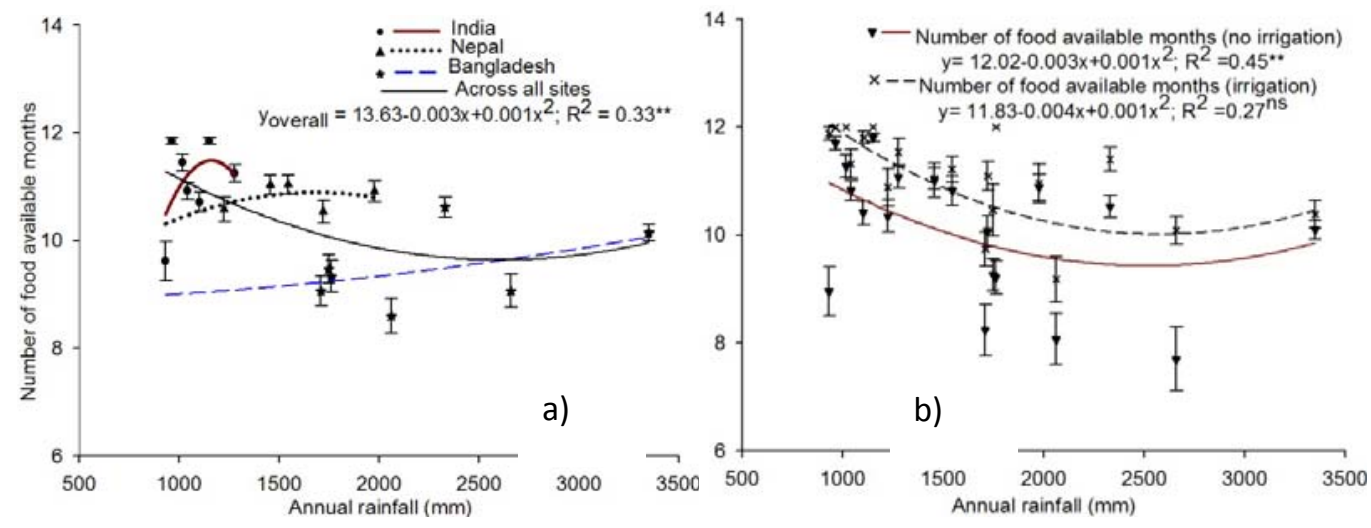

Figure 6. Number of household food available months in a normal year (a) and as per irrigated and non-irrigated farm (b) along the rainfall gradient in IGP (Error bars indicate the 95\% confidence interval of the mean) 


\section{CORRELATION BETWEEN DIFFERENT VARIABLES}

Correlation analysis was done to understand the degree of association between different variables. There is a significant relationship between land holding and on-farm livelihood sources, household assets, number of farm products sold, number of changes made in the farming and number of months of food availability per year (Table1). All of them are positively correlated. Similarly, farmers with more number of on-farm livelihood sources seem to possess more assets and more months of food availability. There is a strong relationship between a proxy measure of household adaptability- the total number of changes made in agricultural practices over the past ten years- and ones for the degree of agricultural diversification and number of farm products sold. This means that households that made more changes are producing a wider range of agricultural products; and conversely, those making few changes tend to be the least diversified households. Correlation test confirms a strong association between the number of changes made and the number of months of food availability. This means that the least food secure households made few changes in their agricultural practices, have relatively poor household assets, and are selling fewer types of agricultural products than more food secure households. This suggests that households that are pursuing adaptation strategies are enhancing their food security, as proposed by others (e.g. Di Falco et al., 2010). Households that had made more changes to their agricultural practices in the past ten years tended to have more assets; and those with few assets were farming in much the same manner as they have been for many years.

Table 1. Correlation between different variables

\begin{tabular}{|c|c|c|c|c|c|c|}
\hline & $\begin{array}{l}\text { On-farm } \\
\text { livelihood } \\
\text { sources }\end{array}$ & $\begin{array}{l}\text { Off-farm } \\
\text { livelihood } \\
\text { sources }\end{array}$ & $\begin{array}{l}\text { Household } \\
\text { assets }\end{array}$ & $\begin{array}{l}\text { Number of } \\
\text { farm } \\
\text { products } \\
\text { sold }\end{array}$ & $\begin{array}{l}\text { Number } \\
\text { of } \\
\text { changes } \\
\text { made }\end{array}$ & $\begin{array}{l}\text { Months of } \\
\text { food } \\
\text { availability }\end{array}$ \\
\hline Land holding & $0.30^{* *}$ & $0.05^{\text {ns }}$ & $0.36^{* *}$ & $0.18^{* *}$ & $0.19^{* *}$ & $0.20^{* *}$ \\
\hline $\begin{array}{l}\text { On-farm } \\
\text { livelihood sources }\end{array}$ & & $0.02^{\mathrm{ns}}$ & $0.46^{* *}$ & $0.57^{* *}$ & $0.53^{* *}$ & $0.18^{* *}$ \\
\hline $\begin{array}{l}\text { Off-farm } \\
\text { livelihood sources }\end{array}$ & & & $0.12^{* *}$ & $0.04^{\mathrm{ns}}$ & $0.20^{* *}$ & $0.12^{* *}$ \\
\hline Household assets & & & & $0.21^{* *}$ & $0.23^{* *}$ & $0.29^{* *}$ \\
\hline $\begin{array}{l}\text { Number of farm } \\
\text { products sold }\end{array}$ & & & & & $0.44^{* *}$ & $0.15^{* *}$ \\
\hline $\begin{array}{l}\text { Number of } \\
\text { changes made }\end{array}$ & & & & & & $0.20^{* *}$ \\
\hline
\end{tabular}

*,** Significant at 0.05 and 0.01 level of probability; ns: non-significant $(p>0.05)$ monotonic 


\section{DISCUSSION}

There are several factors that farmers have to consider to make decision on farming activities, and their ability to adjust with the risks arisen from climatic and non-climatic factors makes some farmers (some regions) more adaptive/innovative than others. Changes in climatic variability and mean values will bring additional complexity in decision making by the smallholder farmers, who are highly vulnerable to these climatic risks (Gregory et al., 2005). The crux of the problem is whether or not climatic variability and change serves as a driver of livelihood diversification. It is obvious assertion that technological innovation in farming does not evolve with respect to climatic factors alone; non-climatic drivers such as market, and other socio-economic and institutional factors also play important and even stronger role. Often it is too complex and difficult to isolate the climatic factors from other driving forces of change (Tschakert, 2007; Raid and Vogel, 2006; Ziervogel et al., 2006; Eakin, 2005). But the impact of climate change and variability becomes more pronounced when there is an interaction with other non-climatic stressors (Mongi et al., 2010). Albeit much is still unknown about characteristics of the future climate, exploring the ways how the farmers with different resource endowments respond to specific climatic conditions can offer insights about how farming community might be able to adapt to future climate. The farmers' livelihood strategy and local adaptation along the climatic and non-climatic resources such as annual rainfall and farm characteristics in IGP needs to be understood for policy implications.

Higher level of on-farm diversification is associated with high amount of rainfall (1300-1800 $\mathrm{mm})$. Both at medium and very high rainfall zones corresponding mostly to Bihar of India and southwest coastal Bangladesh respectively, on-farm diversification are limited. There could be several factors behind it. While salinity, floods and sea level rise are main constraining factors in the coastal Bangladesh, non-climatic factors such as off-farm employment opportunities limit on-farm diversification in Bihar. Livelihood strategies are also the product of the interaction between the portfolio of choices and constraints a farmer have. Since other environmental data and non-climatic information were not collected from the different sites, we are unable to identify other crucial parameters that likely influence livelihoods, farmers' adaptability and household food security. Similarly, climatic resource (such as annual rainfall) may vary in different villages within the same sampling frame $\left(100 \mathrm{~km}^{2}\right)$, that may also affect local livelihoods. Economic background of the farmers also effect on-farm livelihoods. Since we didn't collect information on income and hence we can't establish relationship between household income and livelihood diversification. Ipso facto, farmers across the sites are deriving their livelihoods from multiple sources on the farms and off-farms. As there is no exactly a single livelihood strategy across the sites, diversification of livelihoods is a common strategy followed by the local communities to adapt to uncertainty (Bhatta and Aggarwal, 2015; ICIMOD, 2009), coping with the varieties of risks (Marschke and Berkes, 2006; Turner et al., 2003) and 
ensure food security at the local level (Hailu and Hassen, 2012). The implication of on-farm livelihood diversification is that some of them may be short-term coping mechanisms but some of them may lead to adaptation to vagaries of climatic and non-climatic risks (Marschke and Berkes, 2006).

Availability of irrigation facility enhances on-farm diversification across different rainfall regimes. Assured irrigation facility coupled with better water use efficiency enables farmers to diversify cropping systems and minimize risk from increasing drought spells and erratic rainfall patterns. Furthermore, farmers with irrigation facility can compensate inadequacy of rainfall by means of irrigation, which is an outcome of induced innovation (Chhetri and Esterling, 2012). With assured irrigation, farmers could produce more using inputs. Higher on-farm production also makes food available to the farmers throughout the year. Irrigation as such is not an innovative technology; however, the presence of irrigation expedites adoption of improved technologies such as high-yielding varieties of the crops and the use of agro-chemicals, and also enhances farmers' capacity to adapt to climatic risks (Chhetri and Easterling, 2012).

The off-farm cash sources are higher in the medium rainfall regime $(<1300 \mathrm{~mm})$. Although country-specific regression lines show increasing sources of cash with increasing rainfall regimes, the regression across all sites shows opposite trend. This finding is in congruence with Barret et al. (2005) and Babulo et al. (2008) who found that crop production alone is less likely to cover even the household consumption requirements in relatively lesser rainfall areas and hence farmers go for off-farm diversification to minimize risks. Similarly, Mertz et al. (2010) found that income from rainfed crops and/or livestock are mostly frequently mentioned in the wetter zone and migration based income, particularly through remittance, is important in the drier zone. The opposite movement of regression line also implies that there is interaction of socio-economic and biophysical factors with rainfall amount. This could be a good finding that livelihood strategies are location specific and policies aimed for a broader geographical area would have less meaning.

Individual farm-family and farming community are used to adapting to a range of environmental and socio-economic stresses (Bhatta and Aggarwal, 2015; Ojha et al., 2014). At the farm level, adaptation to climatic variability includes changes in farming practices (farm technologies and the way of farming). Adaptation may occur in relation to, for instance, agronomic or fisheries aspects regarding food production; or pricing policies and market opportunities (Kristjanson et al., 2012; Gregory et al., 2005). Some of these adaptations are not responses that are unique to climate disturbances, such as diversifying livelihoods, but importantly have been clearly identified in this research as deliberate consequences of climate triggers. These adaptations occur in order to change the nature of the risks when living in a variable and changing climatic system. 
Many of the farm practices changed in IGP sites are related to crop and varieties. Kristjansen et al. (2012) also found that crops and/varieties are frequently changed over the last decade in East Africa. Varietal adoption alone, however, will have limited impacts on agricultural production, especially in the resource scarce areas. Farmers under such environment use different production technologies to avail the benefit from the new varieties. The development of suitable varieties, adoption of modern tools, and increased access to agro-inputs make varietal efforts more profitable in risk-prone environments (Pandey and Velasco, 2002). In general terms, we could state that all practices directed towards the success of cultivated crops are essential to food security, not only in the context of climate change. This is so because crop cultivation is subjected to the variability and unpredictability of weather events and pests and diseases, thus, all practices enhancing crop survival can be valid for climate change adaptation.

\section{CONCLUSION}

The implication of climatic and non-climatic resources such as rainfall and farm types on livelihood diversification, household food security and farmers' adaptation remain understudied in IGP. We found that farmers in the medium rainfall regime diversify less on the on-farm but more on the off-farm activities, indicating that agriculture is becoming less important in medium rainfall zone. On contrary, the farmers in the medium rainfall regimes often cope with the changing circumstances by frequently altering farming practices. They also have relatively lower number of food deficit months compared to those at high and very high rainfall regimes. Although agricultural production and local adaptation are restrained by several climatic and non-climatic factors; the amount of annual rainfall significantly affects livelihood diversification, and the impact of climatic stressors becomes more pronounced when there is interaction with other non-climatic factors. For instance, irrigation availability has shown higher number of on-farm livelihood options, more number of changes in farming practices over time and higher food security along the spatial gradient of rainfall. This proves that farming systems operate better in the presence of non-climatic resources, which could somehow counteract the impact of climatic stressors. The study also finds that resource rich farmers (such as those having irrigation on the farm) are better adapted, well diverse in terms of livelihood sources and have food available almost throughout the year than resource poor farmers (those who don't have irrigation). Therefore, in order to promote livelihood and adaptation under changing climatic conditions, resource poor farmers should be given proper care and provision of irrigation should be established.

Household perception of current and future adaptation needs point to important measures that are not directly climate-related. It makes sense that these more immediate and visible drivers have significantly greater influence on food insecure smallholder farmers than do concerns over long-term changes in the climate. Emphasis on increasing agricultural 
productivity is the imperative if the smallholders, who are reeling under tremendous environmental and socio-economic pressure with many roots in climate change, have to feed themselves. This is most likely also the case in similar regions in other parts of South Asia and the tropics and sub-tropics, particularly in the areas with a large concentration of smallholder subsistence farming predominates

\section{ACKNOWLEDGEMENTS}

The authors wish to express our gratitude to all members of site survey team for their hard work in collecting data. We would like to thank all interviewees in the local communities in different countries. Thanks are due to Patti Kristjanson for providingconstructive suggestions and required inputs in this study. We appreciate the support from CCAFS's numerous investors and CGIAR centre colleagues and partners. CCAFS baseline work was carried out with funding by the European Union (EU) and with technical support from the International Fund for Agricultural Development (IFAD).

\section{REFERENCES}

Aggarwal, P.K.,P.K. Joshi, J.S.I. Ingram, R.K. Gupta. 2004. Adapting food systems of the IndoGangetic plains to global environmental change: key information needs to improve policy formulation. Environmental Science and Policy, 7(6):487-498, Doi: 10.1016/j.envsci.2004.07.006

Ahmed, A. U., S. R. Hassan, B. Etzold and S. Neelormi.2012. Where the rain falls, case study: Bangladesh. United Nations University and Institute for Environment and Human Security (UNUEHS), Bonn, p. 156.

Babulo, B., B. Muys, F. Nega, E. Tollens, J. Nyseen, J. Decker, E. Mathijs. 2008. Household livelihood strategies and forest dependence in the highlands of Tigray, Nothern Ethiopia. Agricultural Systems, 98:147-155, doi:10.1016/j.agsy.2008.06.001

Barrett, C., P.P. Marenya, J.G. McPeak, B. Minten, F.M. Murithi, W. Oluoch-Kosura, F. Place, J.C. Randrianarisoa, J. Rasambainarivo, J. Wangila. 2006. Welfare dynamics in rural Kenya and Madagascar. Journal of Development Studies, 42(2):248-277,Doi: 10.1080/00220380500405394

Barrett, C.B., M. Bezuneh, D. Clay, T. Reardon. 2005. Heterogeneous constraints, incentives and income diversification strategies in rural Africa. Quarterly Journal of International Agriculture, 44(1):37-60.

Barrett, C.B. and T. Reardon. 2001. Nonfarm income diversification and household livelihood strategies in rural Africa: concepts, dynamics, and policy implications. Food Policy, 26(4): 315331.

Bhatta, G.D. and P.K. Aggarwal, 2015. Coping with weather adversity and adaptation to climatic variability: a cross-country study of smallholder farmers in South Asia. Climate and Development, Doi: $\underline{10.1080 / 17565529.2015 .1016883}$

Brown, R., C. Stephens, J. Ouma, M. Murithi, C. Barrett. 2006. Livelihood strategies in the rural Kenyan highlands. African Journal of Agriculture Resource Economics, 1(1):21-36.

Chhetri, N. and W. Easterling. 2012. Adapting to climate change: Retrospective analysis of climate technology interaction in the rice-based farming system of Nepal. Annals American Geographers, 100(5):1156-1176, doi: 10.1080/00045608.2010.518035 
CRU, 2013. University of East Anglia Climatic Research Unit. CRU TS3.21: Climatic Research Unit (CRU) Time-Series (TS) version 3.21 of high resolution gridded data of month-by-month variation in climate (Jan. 1901- Dec. 2012). Data extracted in April 2013.

Cooper, P.J.M., J.Dimes, K.P.C.Rao, B.Shapiro, B.Shiferaw and S. Twomlow,2008. Coping better with current climatic variability in the rain-fed farming systems of sub-Saharan Africa: An essential first step in adapting to future climate change? Agriculture, Ecosystems and Environment, 126:24-35, doi: 10.1016/j.agee.2008.01.007

Di Falco, S., M.Veronesi, M. Yesuf, 2010. Does adaptation to climate change provide food security? A micro-perspective from Ethiopia. Grantham Research Institute on Climate Change and Environment, Working Paper No. 19.

Eakin, H., 2005. Institutional change, climate risk, and rural vulnerability: cases from central Mexico. World Development, 33:1923-1938, doi: 10.1016/j.worlddev.2005.06.005

FAO, 2002. World agriculture: towards 2015/2030. Summary Report.

Gebru, G.W. and F. Beyene,2012. Rural household livelihood strategies in drought-prone areas: A case of Gulomekeda District, eastern zone of Tigray National Regional State, Ethiopia. Journal of Development and Agricultural Economics, 4(6):158-168.

GECAFS, 2008. GECAFS indo-gangetic plain science plan and implementation strategy. GECAFS Report, 5:35.

Gill, G.J., J.Farrington, E.Anderson, C.Luttrell, T.Conway, N.C.Saxena, R. Slater, 2003. Food Security and the Millennium Development Goal on Hunger in Asia. Working Paper 231. ODI, London.

Gregory, P.J., J.S.I. Ingram and M. Brklacich, 2005. Climate change and food security. Philosophical Transactions of the Royal Society Biological Sciences, 6:2139-2148, doi: 10.1098/rstb.2005.1745

Gupta, R.K. and A. Seth,2007. A review of resource conserving technologies for sustainable management of the rice-wheat cropping system of the Indo-Gangetic Plains (GCP). Crop Protection, 26:436-447, doi: 10.1016/j.cropro.2006.04.030

Hailu, R. and A. Hassen, 2012. Livelihood diversification among the agricultural land scarce peasants in the Central highlands of Ethiopia. International Journal of Agricultural Science, Research and Technology, 2(1):1-8.

Harrington, L.W. and P.R.Hobbs, 2009. The Rice-Wheat Consortium and the Asian Development Bank: A history. In: J.K. Ladha, Yadvinder-Singh; O. Erenstein and B. Hardy(eds.) Integrated crop and resource management in the rice-wheat system of South Asia. International Rice Research Institute (IRRI), Los Baños, Philippines. p 3-68.

Hesterman, O.B. and T.L. Thorburn,1994. A comprehensive approach to sustainable agriculture: W.K. Kellog'a Integrated Farming Systems Initiative. Journal of Production Agriculture, 7:133.

ICIMOD, 2009. Local responses to too much and too little water in the greater Himalayan region. International Centre for Integrated Mountain Development, Kathmandu, Nepal.

IPCC, 2007. Climate change 2007: Working Group II: impacts, adaptation and vulnerability. Appendix I: Glossary. In: IPCC Fourth Assessment Report: Climate Change 2007.

Karim, M.F. and N.Mimura, 2008. Impacts of climate change and sea-level rise on cyclonic storm surge floods in Bangladesh. Global Environmental Change, 18:490-500, doi: 10.1016/j.gloenvcha.2008.05.002

Kristjanson, P., H. Neufeldt, A. Gassner, J. Mango, F. Kyazze, S. Desta, G. Sayula, B. Thiede, W. Förch, P.K, Thornton and R.Coe, 2012. Are food insecure smallholder households making changes in their farming practices? Evidence from East Africa. Food Security, 4(3):381-397, doi: $\underline{10.1007 / \mathrm{s} 12571-012-0194-\mathrm{z}}$ 
Ladha, J.K., V. Kumar, M.M. Alam, S. Sharma, M.K. Gathala, P. Chandna, Y.S. Sahrawat, and V.Balasubramanian, 2009. Integrating crop and resource management technologies for enhanced productivity, profitability, and sustainability of the rice-wheat system in South Asia. In: J.K. Ladha, Yadvinder- Singh, O., Erenstein and B. Hardy(eds.) Integrated crop and resource management in the rice-wheat system of South Asia, International Rice Research Institute (IRRI), Los Baños, Philippines. p 69-108.

Marschke, J.M. and F. Berkes,2006. Exploring strategies that build livelihood resilience: a case from Cambodia. Ecology and Society, 11(1):42-58.

Mertz, O., C.Mbow, J.O.Nielsen, A.Maiga, D.Diallo, A.Reenberg, A.Diouf, B.Barbier, I.B.Moussa, M.Zorom, I. Ouattara and D. Dabi, 2010. Climate factors play a limited role for past adaptation strategies in West Africa. Ecology and Society, 15(4):25-39.

Mirza, M.M.Q., R.A.Warrick and N.J.Ericksen, 2003. The implications of climate change on floods of the Ganges, Brahmaputra and Meghna rivers in Bangladesh. Climatic Change, 57:287-318, doi: 10.1023/A:1022825915791

Mongi, H., A.E. Majule and J.G. Lyimo, 2010. Vulnerability and adaptation of rainfed agriculture to climate change and variability in semi-arid Tanzania. African Journal of Environmental Science and Technology, 4(6):371-381.

Nelson, G.C., M.W. Rosegrant, J. Koo, R. Robertson, T. Sulser, T. Zhu, C. Ringler, S. Msangi, A. Palazzo, M. Batika, M. Magalhaes, R. Valmonte-Santos, M. Ewing and D Lee, 2009. Climate change: impact on agriculture and cost of adaptation. Food Policy Report 21, International Food Policy Research Institute (IFPRI), Washington DC, USA.

New, M., M. Rahiz and J. Karmacharya, 2012. Climate change in indo-gangetic agriculture: recent trends, current projections, crop-climate suitability, and prospects for improved climate model information. CGIAR Research Program on Climate Change, Agriculture and Food Security (CCAFS). Copenhagen, Denmark.

Nicholls, R.J., P.P. Wong, V.R. Burkett, J.O. Codignotto, J.E. Hay, R.F. McLean, S. Ragoonaden and C.D. Woodroffe, 2007. Coastal systems and low-lying areas. Climate Change 2007: Impacts, Adaptation and Vulnerability. Contribution of Working Group II to the Fourth Assessment Report of the Intergovernmental Panel on Climate Change, M.L. Parry, O.F. Canziani, J.P. Palutikof, P.J. van der Linden and C.E. Hanson, Eds., Cambridge University Press, Cambridge, UK, 315356.

Ojha, H. R., R. Sulaiman, P.Sultana, K.R.Dahal, D.Thapa, N.Mittal,G.D. Bhatta and P.K. Aggarwal, 2014. Is South Asian agricultureadapting to climate change? Evidence from the Indo-Gangetic Plains. Agroecology and Sustainable Food Systems, 38(5),505-531. Doi: $10.1080 / 21683565.2013 .841607$

Pandey, S. and L. Velasco, 2002. Economics of direct seeding in Asia: patterns of adoption and research priorities. In: Pandey, S., M. Mortimer, L. Wade, T.P. Tuong, K. Lopez and B. Hardy (eds.): Direct seeding: research issues and opportunities. Proceedings of the International Workshop on Direct Seeding in Asian Rice Systems: Strategic Research Issues and Opportunities. 25-28 January 2000, Bangkok, Thailand. International Rice Research Institute, Los Banos, Philippines: 3-14.

Reid, P. and C. Vogel, 2006. Living and responding to multiple stressors in South Africa-Glimpses from KwaZulu-Natal. Global Environmental Change, 16:195-206, doi: 10.1016/j.gloenvcha.2006.01.003 
Saini, H.S., 2008. Climate change and its future impact on the Indo-Gangetic Plain (IGP). E-Journal Earth Science, 1(3):138-147.

Slingo, J.M., A.J. Challinor, B.J. Hoskins and T.R. Wheeler, 2005. Food crops in a changing climate. Philosophical Transactions of the Royal Society Biological Sciences, 360(1463):1983-1989, doi: $\underline{10.1098 / \text { rstb.2005.1755 }}$

Teweldemedhin, M.Y. and Y. Kapimbi, 2012. Factors influencing enterprise diversification as a risk strategy management in Namibia: A case study of communal farmers from the Kunene region. International Journal of Agriculture Science, 2(9):845-853.

Thornton, P.K., R.B.Boone, K.A.Galvin, S.B.BurnSilver, M.M.Waithaka, J.Kuyiah, S.Karanja, E.González-Estrada, and M.Herrero, 2007. Coping strategies in livestock-dependent households in East and southern Africa: A synthesis of four case studies. Human Ecology, 35(4):461-476, doi: $10.1007 / \mathrm{s} 10745-007-9118-5$

Tschakert, P., 2007. Views from the vulnerable: understanding climatic and other stressors in the Sahel. Global Environmental Change, 17:381-396, doi: 10.1016/j.gloenvcha.2006.11.008

UNDP, 2009. United Nation Development Program http://hdr.undp.org/en/reports/global/hdr2009/

Ziervogel, G, S. Bharwani and T.E. Downing, 2006. Adapting to climate vulnerability: pumpkins, people and policy. Natural Resources Forum, 30:294-305, doi: 10.1111/j.1477$\underline{8947.2006 .00121 . x}$ 